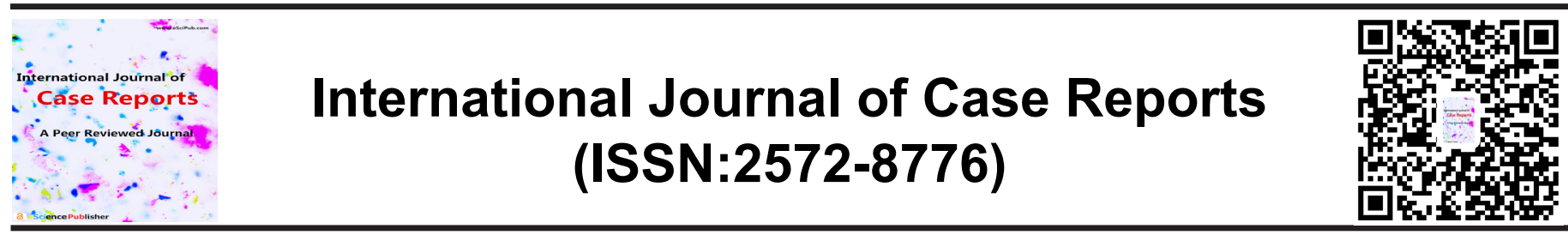

\title{
Giant hydronephrosis in an 82-year-old woman with multiple comorbidities: a case report
}

Bouveret P. ${ }^{1}$, Robinet P. ${ }^{1}$, Brocquet E. ${ }^{1}$, Averlant L. ${ }^{1}$, Maladry F. ${ }^{1}$, Delecluse C. ${ }^{1}$, Visade F. ${ }^{1^{*}}$

${ }^{1}$ Department of Geriatrics, Lille Catholic Hospitals, University of Lille, Lomme F-59160, France.

\begin{abstract}
Giant hydronephrosis is a rare urinary tract disorder characterized by a collection arising from the kidney. Because Visade F.

of its complications, surgery remains the main treatment. Department of Geriatrics, Lille CatHere we report the case of an 82-year-old woman with holic Hospitals, University of Lille, multiple comorbidities and diagnosis of giant hydronephrosis. Lomme F-59160, France.

After multidisciplinary concertation between urologists and geriatricians, no specific treatment was initiated. This case report How to cite this article:

highlights a non-specifically presentation of this rare disorder, Bouveret P., Robinet P., Brocquet E., including no symptom. The presence of multiple comorbidities Averlant L., Maladry F., Delecluse has changed the management commonly reported in the C., Visade F.. Giant hydronephrosis literature. in an 82-year-old woman with multiple comorbidities: a case report.

Keywords: Giant hydronephrosis; Multiple comorbidities International Journal of Case Reports, 2021; 5:216.

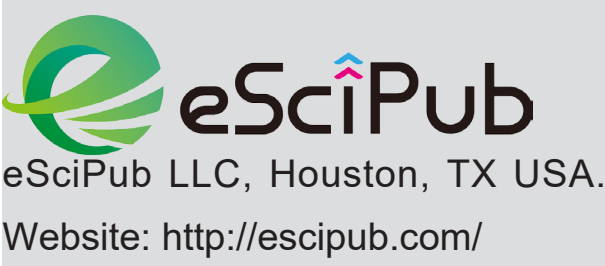




\section{Background}

Giant hydronephrosis is a rare urinary tract disorder characterized by a collection arising from the kidney that occupies half of the abdominal cavity or crosses the midline. This pathology is defined by the presence of more than $1000 \mathrm{ml}$ of fluid in the renal collection system. Ureteropelvic junction obstruction is the main etiology ${ }^{[1]}$.

In young adults, giant hydronephrosis can be clinically associated with abdominal pain, nausea or vomiting. Many complications may occur like intestinal obstruction or venous compression. Surgery remains the main treatment. In older patients, atypical clinical signs are often present, especially when associated with cognitive impairment. In this case, the medical management may be different, and no recommendation exist. However, there are few studies on the diagnosis of giant hydronephrosis in older patients with cognitive disorders.

Here we present a case of giant hydronephrosis diagnosed in an older female patient with multiple comorbidities including cognitive impairments.

\section{Case presentation}

The patient was an 82-year-old female with multiple comorbidities: arterial hypertension, heart failure with NYHA stage 2 dyspnea, diffuse atheroma, pulmonary embolism due to deep vein thrombosis, recurrent urinary tract infections, a hiatus hernia, total right hip replacement, vertebral fractures, cognitive impairment, and chronic psychosis.

The patient lived in a nursing home with relative independence in activities of daily living. The patient needed a toilet and dressing aid. She walked alone without technical assistance. Occasionally, the patient presented with urinary incontinence. The ADL score ${ }^{[2]}$ was $4.5 / 6$.

The patient was referred to the emergency department in a context of repeated falls occurring for 24 hours, with loss of dependence in walking abilities. In this context, X-rays of the pelvis and the hips were performed. No fractures or dislocations were visible.

The patient was then hospitalized in the geriatric ward. During her stay, because of persistent pain in the right iliac fossa, an abdomino-pelvic scan was performed. CT imaging showed major dilation of the right pyelocaliceal cavities without dilation of the right ureter with an appearance suggestive of junction syndrome.

A urological opinion was requested and led to the diagnosis of hydronephrosis of the right kidney on an obstruction of the very old uretero-pelvic junction. No specific treatment has been initiated but in the event of symptoms (sudden abdominal pain, vomiting) the place -ment of a JJ stent has been proposed. The risk of retroperitoneal hematoma after a fall has also been noted.
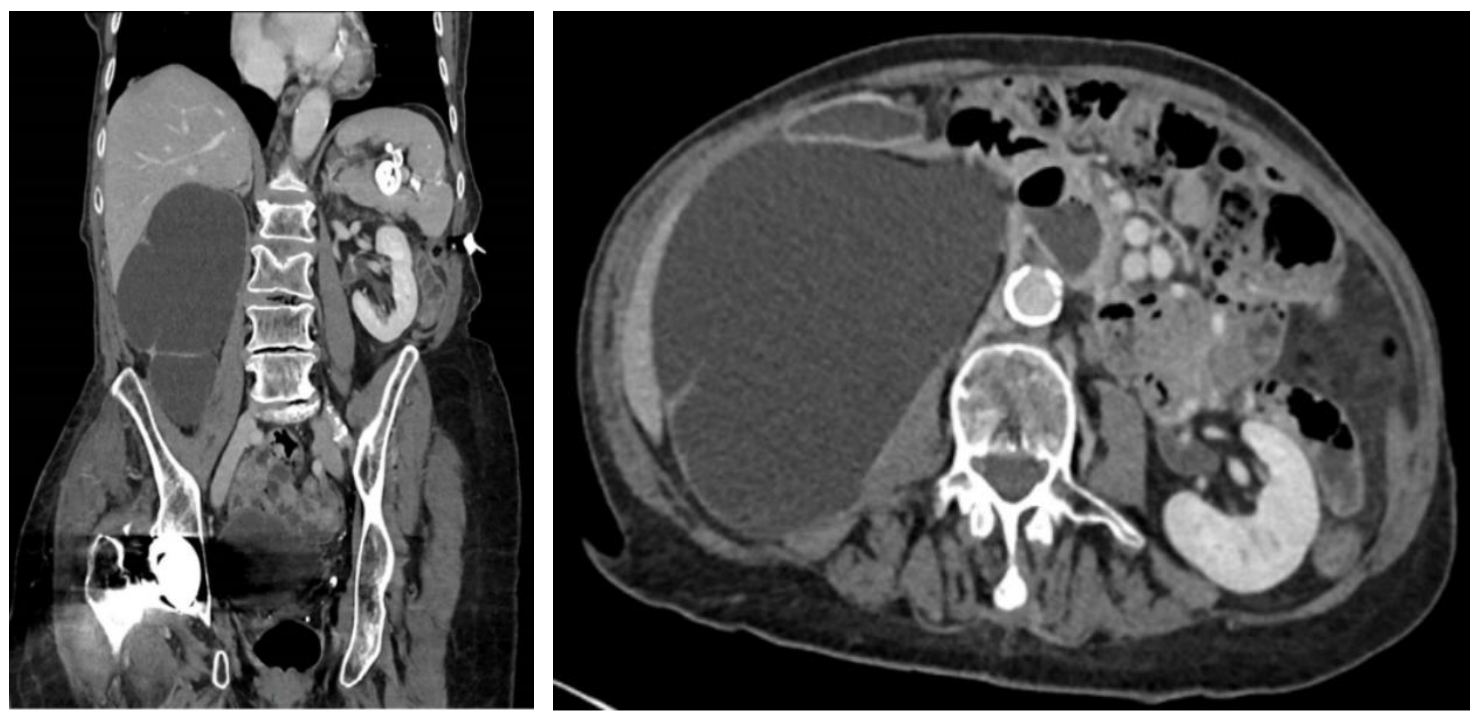

IJCR: https://escipub.com/international-journal-of-case-reports/ 


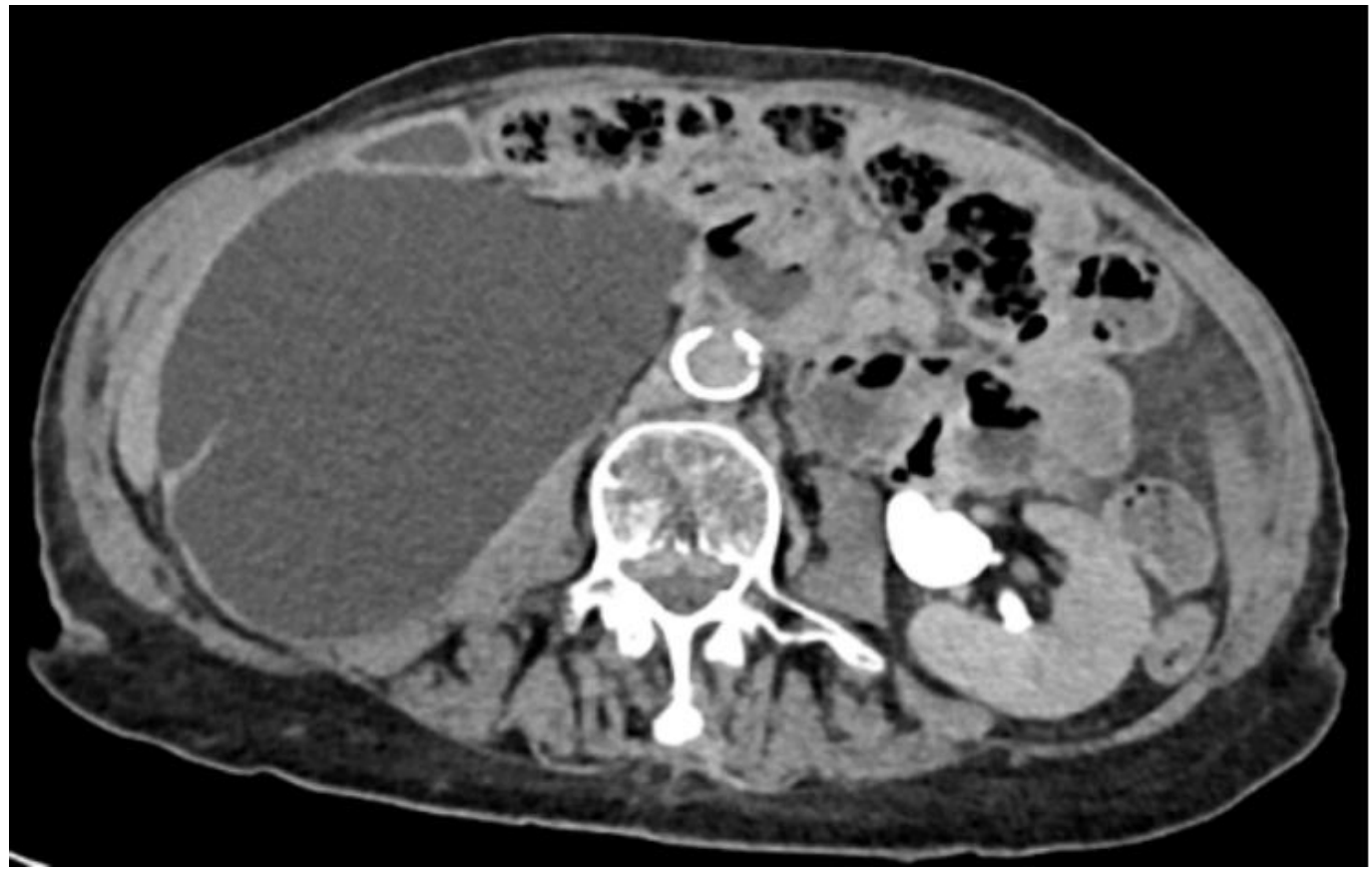

Urinary excretion via the left kidney halted on the right due to the hydronephrosis

\section{Discussion}

Giant hydronephrosis is a relatively rare condition. Between 1910 and 1990, only 523 cases were reported in the literature ${ }^{[3]}$. This pathology is defined as the presence of more than 1000 $\mathrm{ml}$ of fluid in the renal collection system [3, 4]. Crooks et al. defined giant hydronephrosis as a collection originating from the kidney and occupying half of the abdomen or crossing the midline ${ }^{[5]}$. Hydronephrosis is often associated with very significant atrophy of the renal parenchyma ${ }^{[6]}$.

The most common etiology is obstruction of the uretero-pelvic junction. Other causes have also been described by Golcuk et al. such as trauma, lithiasis, ureteral tumors, and renal ectopia [7].

Clinically, hydronephrosis presents as an abdominal mass associated with nausea, vomiting and abdominal pain ${ }^{[8]}$. This may sometimes lead to digestive compression responsible in particular for constipation or even intestinal obstruction, venous compression responsible for edema of the lower limbs. Hydronephrosis can also be the cause of dyspnea or even respiratory distress due to diaphragmatic repression $[9,10,11]$. Some patients describe he- maturia, this symptom should lead to the search for associated lithiasis or the presence of neoplasia ${ }^{[12]}$. Computed tomography urography is the imaging exploration of choice for diagnostic and etiological workup.

Regarding management, nephrectomy is the standard treatment, especially when the other kidney is functioning properly ${ }^{[13]}$. Most clinicians offer preventive antibiotic therapy to cover the procedure. Given the risks in the event of surgical management, percutaneous drainage can also be offered. In the situation where the kidney presents a parenchymal thickness of more than $1 \mathrm{~cm}$ associated with glomerular filtration greater than $20 \mathrm{~mL} / \mathrm{min}$, conservative treatment may be considered [14, 15].

In older patients, clinical signs may go unnoticed due to the presence of cognitive impairments. A non-specifically presentation may be possible, including no symptom. In our case, comorbidities were associated, and surgical treatment could have caused many postoperative complications, like decompensation of a chronic disease, delirium or autonomy loss. Only careful management while preventing any complications was decided. It consisted in the 
prevention of falls in this patient with history of multiple falls.

\section{Conclusion}

We present a case of giant hydronephrosis in pyelo-ureteral junction syndrome, discovered in an older female patient with comorbidities including cognitive impairments. Unlike younger patients, for whom surgery or percutaneous drainage remains the main treatment, careful management with prevention of any complications, was decided.

\section{Bibliographie}

[1] Grover CA, Crisp JG. Giant hydronephrosis presenting as an acute abdomen. J Emerg Med. nov 2012;43(5):e307-310.

[2] Katz S, Downs TD, Cash HR, Grotz RC. Progress in Development of the Index of ADL1. The Gerontologist. 1 mars 1970;10(1_Part_1): 20-30.

[3] Chiang $\mathrm{PH}$, Chen MT, Chou YH, Chiang CP, Huang $\mathrm{CH}$, Chien $\mathrm{CH}$. Giant hydronephrosis: report of 4 cases with review of the literature. J Formos Med Assoc Taiwan Yi Zhi. sept 1990;89(9):811-7.

[4] Agarwal MM, Sharma D, Singh SK, Kumar S, Bhattacharya A, Acharya N, et al. Laparoscopic ureterocalicostomy for salvage of giant hydronephrotic kidney: initial experience. Urology. sept 2007;70(3):590.e7-10.

[5] Crooks KK, Hendren WH, Pfister RC. Giant hydronephrosis in children. J Pediatr Surg. déc 1979;14(6):844-50.

[6] Benhaddou H, Bellahcen M, Elazzouzi D. Giant hydronephrosis in a child: case report. Arch Pediatr Organe Off Soc Francaise Pediatr. oct 2013;20(10):1126-8.
[7] Golcuk Y, Ozsarac M, Eseroglu E, Yuksel MB. Giant Hydronephrosis. West J Emerg Med. juill 2014;15(4):356.

[8] Diallo Y, Dia A, Kouka SC, Ondo C, Sow Y, Fall $B$, et al. L'hydronéphrose géante: a propos de 3 cas et revue de la littérature. undefined [Internet]. 2014 [cité 29 mars 2021]; Disponible sur:

/paper/L\%E2\%80\%99hydron\%C3\%A9phrose-g $\%$ C3\%A9ante\%3A-a-propos-de-3-cas-et-revueDiallo-Dia/7834f318dbc758bcdacd2314f7c6cd6 24aa62b42

[9] al Saleh BM, Hadi AQ, Abdin MW. Giant hydronephrosis. Br J Urol. déc 1992;70(6): 686 -7 .

[10] Kaya C, Pirincci N, Karaman MI. A Rare Case of an Adult Giant Hydroureteronephrosis due to Ureterovesical Stricture Presenting as a Palpable Abdominal Mass. Int Urol Nephrol. 1 déc 2005;37(4):681-3.

[11] Ansari MS, Singh I, Hamal AK. Giant hydronephrotic kidney mimicking intestinal obstruction. Int Urol Nephrol. 1 sept 2003;35(3):319 -20 .

[12] Sangisetty KV, Randrup ER. Congenital giant hydronephrosis with unsuspected transitional cell carcinoma. Urology. oct 1985;26(4):400-1.

[13] Jardin A. Hydronéphrose : Éditions techniques. Ency Med Chir (Paris France), Néphrologie -Urologie, 18157 P15, 1991

[14] Diao B, Fall PA, Ngom GM, Sow Y, Thiam A, Ndoye AK, et al. Article Original Hydronéphrose géante de l'enfant: Aspects diagnostiques et thérapeutiques. Afr J Urol. 23 oct 2008;14(3): 168-73.

[15] Oka N, Hasegawa T, Ando Y. Considerations on the worthful recovery of renal function in hydronephrosis. Nihon Hinyokika Gakkai Zasshi Jpn J Urol. févr 1972;63(2):83-95.

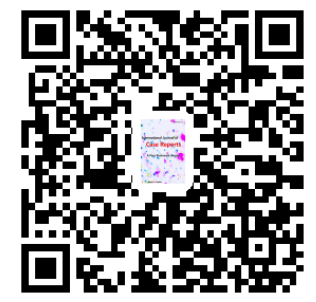

